\title{
Fairness as a Determinant of the Jigsaw Procedure's Success in Teaching Undergraduate Psychological Statistics
}

\author{
Angela P. Cole-Dixon ${ }^{1}$, Angela D. Glymph-Austin ${ }^{1}$, Janel M. Gill ${ }^{1}$, Cassandra A. Shivers-Williams ${ }^{1} \&$ Debra D. $^{2}$ \\ Roberts $^{1}$ \\ ${ }^{1}$ Howard University, Washington, USA \\ Correspondence: Angela P. Cole-Dixon, Professor of Psychology, Howard University, 2400 6th Street, NW, \\ Washington, DC 20059, USA.
}

Received: January 10, 2019

Accepted: February 15, 2019

Online Published: March 11, 2019

doi:10.5430/irhe.v4n1p9

URL: https://doi.org/10.5430/irhe.v4n1p9

This research was supported by a New Awards for Research on Teaching/ Learning Program Grant from the Howard University Graduate School and the Woodrow Wilson Foundation.

\begin{abstract}
Undergraduate students $(n=46)$ completed four lab assignments (two "jigsaw group" assignments and two more traditional individual statistics lab assignments), followed by quizzes and evaluations of their assignments, instructor, and classmates, in a study designed to confirm and extend previous findings of positive effects of the jigsaw procedure in a psychological statistics course. Findings of the study (a) showed expected quiz performance improvement following jigsaw assignments, (b) provided preliminary support for Aronson's and colleagues' position that the success of the jigsaw classroom is due in part to decreased perceptions of unfairness, and (c) further established the ecological validity of fair process effects in a setting not previously investigated-the jigsaw classroom. Moreover, our findings suggest that the jigsaw procedure is well-suited for supplementing psychological statistics lectures.
\end{abstract}

Keywords: jigsaw classroom, fairness, psychological statistics

\section{Introduction}

Several studies concerned with effective strategies for teaching psychology have documented the special challenges associated with teaching statistics. Conners, Mccown, and Roskos-Ewoldsen (1998, pp. 40-41) pointed out that statistics is harder to relate to, evokes considerably higher levels of anxiety and apprehension, is less likely to be retained, and is less easily applied than many other psychology courses. Despite these difficulties, mastery of statistics is a requisite for success in the discipline of psychology. Not only is statistics an integral part of the language and science of psychology, but also it helps form the foundation of the scientific approach taken by psychologists (Abrami, Cholmsky, \& Gordon, 2001; Kerlinger \& Lee, 2000). Therefore, it is essential that professors implement innovative teaching strategies to increase undergraduate psychology majors' likelihood of and commitment to mastering statistics, as well as to facilitate their retention and application of this subject.

The "jigsaw classroom" (Aronson, 1990, 2002; Aronson, Blaney, Sikes, Stephan, \& Snapp, 1975; Aronson \& Bridgeman, 1979) is one such innovative strategy. It incorporates in its pedagogical approach insights from seminal social psychological studies of social facilitation, social loafing, cooperation, and competition (Cottrell, Wack, Sekerak, \& Rittle, 1968; Darley \& Latané, 1968; Deutsch, 1949; Latané, Williams, \& Harkins, 1979; Sherif, Harvey, White, Hood, \& Sherif, 1961; Zajonc, 1965). The jigsaw procedure emphasizes collaboration and cooperation, without diminishing the importance of each individual's role or restricting autonomy (Aronson, 2002). For example, in one study, students worked in small groups and were given unique roles as follows:

We placed students in six-person, multi-ethnic learning groups, divided the lesson into six parts, and asked each student to learn his or her segment and recite it to other members of the group. We made certain that the only access each student had to the five segments other than his or her own was through listening to the recitations of the groupmates. We then administered a test to the students on the entire lesson (Aronson, 1990, pp. 120-121).

Numerous studies (e.g., Brookfield \& Preskill, 1999; Carroll, 1986; Crone \& Portillo, 2013; Langlois, 2001; Perkins 
\& Saris, 2001; Şahin, 2011; Walker \& Crogan, 1998) have found the jigsaw procedure is extremely effective in a variety of teaching settings, including statistics. Consistent with theorizing by Aronson and Bridgeman (1979), a repeated finding in these studies is that the procedure's success is due largely to its positive effects on students' participation, cooperation, empathy, interdependence, and attributions. A related Aronson and Bridgeman (1979) hypothesis, which has attracted relatively little empirical study, highlights the jigsaw procedure's positive effects on students' perceptions of fairness and perceptions about their relative status in the class. Given the volume of procedural fairness literature that supports this hypothesis (e.g., Brockner \& Wiesenfeld, 1996; Chen, Brockner, \& Greenberg, 2003; De Cremer, Brockner, Fishman, van Dijke, van Olffen, \& Mayer, 2010; Grootelaar \& van den Bos, 2018), this paucity is surprising. The present study examines further the process through which the jigsaw procedure works and the role of fairness considerations in that process in the context of an undergraduate psychology research methods and statistics course.

\subsection{Research on Procedural Justice}

Procedural fairness has been described as among the most fundamental of motivations (De Cremer \& Van Hiel, 2008; Folger, 1984; Miedema, van den Bos and Vermunt, 2006; van den Bos and Miedema, 2000). A repeated finding in the procedural fairness literature (Lind \& Tyler, 1988; Tyler, 1989; 1994; van den Bos, 2001, 2003; van Prooijen, van den Bos \& Wilke; 2002, 2004, 2005) is that perceived fairness is a primary determinant of individuals' satisfaction with procedures, satisfaction with outcomes, perceptions of authorities' legitimacy, and commitment to groups, institutions, and practices. For example, Tyler and Caine (1981) conducted two studies that examined the effects of procedural fairness and outcome favorability on students' ratings of grades, grading procedures, and instructors. In the first study, the fairness of grading procedures and favorability of students' class outcomes (grades) were varied systematically in vignettes, while the second study examined participants' reflections on their own positive or negative classroom experiences. Both studies found that procedural fairness consistently exerted significant positive influence on ratings of fairness of grading procedures, fairness of grades, satisfaction with grading procedures, satisfaction with grades, and on students' evaluations of instructors, even when students' outcomes were unfavorable.

The effects of procedural fairness on subsequent judgments about outcomes, procedures, authorities, institutions, and practices are labeled "fair process effects" (Folger, Rosenfield, Grove, \& Corkran, 1979; Hildreth, Moore, \& Blader, 2014; van den Bos, 1999; van den Bos, Bruins, Wilke, \& Dronkert, 1999; van den Bos, Lind, Vermunt, \& Wilke, 1997). Procedural fairness has been conceptualized as reflecting concerns about both the utility of a procedure for achieving one's desired outcomes ("instrumental" concerns), and one's relationships and relative status within groups ("relational" concerns). Indeed, Thibaut's and Walker's (Thibaut \& Walker, 1975, 1978) instrumental model posits that procedural fairness judgments depend on the extent to which procedures maximize individuals' control over outcome allocations. Numerous studies in this tradition (e.g., Houlden, LaTour, Walker, \& Thibaut, 1974; LaTour, 1978; Walker, LaTour, Lind, \& Thibaut, 1974) have demonstrated the dependence of procedural fairness judgments on the extent to which procedures (a) take effort into account, and (b) allow individuals opportunities to present their views (labeled "voice"). Within this instrumental model, fair process effects result because self-interest motivates individuals to maximize their outcomes.

In contrast, Lind's and Tyler's (Lind \& Tyler, 1988; Tyler \& Lind, 1992) group value theory emphasizes relational concerns, maintaining that fair process effects result because people derive important information about their status within a group from the degree to which they are treated fairly by authorities. Studies in this tradition (e.g., Heuer, Penrod, Hafer, \& Cohn, 2002; Tyler, 1989; Tyler, Degoey, \& Smith, 1996; van Prooijen, van den Bos \& Wilke; 2002) also highlight the importance of voice as a determinant of procedural fairness judgments. Here, however, high-voice procedures are valued not simply because they increase individuals' control over their outcomes. Rather, high-voice procedures also are assumed to convey more positive messages about individuals' social standing than low-voice procedures and are perceived, consequently, as more satisfactory. Unfair experiences lead to decreased levels of group commitment, less willingness to participate in group activities, and diminished cooperation with and contributions to groups (Tyler, 1994; Tyler \& Degoey, 1995; Tyler, Degoey, \& Smith, 1996).

Taken together, the findings of the procedural fairness literature would suggest that increases in students' fairness perceptions of instructional procedures lead to (a) increased satisfaction with instructional procedures and with grades; (b) more positive attributions about students' relationships with instructors and classmates and their relative status in the class; (c) increased commitment to learning, active participation, contributions, and cooperation in class; and, consequently, (d) increased class performance.

\subsection{Research on the Jigsaw Procedure}

Past studies of the jigsaw procedure have focused largely on two sources of evidence to establish its effectiveness: 
student evaluations and mastery of concepts covered in jigsaw exercises. For example, Perkins and Saris (2001, p. 112) found in an undergraduate statistics course that more than 50\% of the students gave very positive evaluations of a jigsaw procedure when rating its usefulness for "getting help," "giving help," "working with classmates," "providing an alternative to lecture," "saving time," and "understanding the statistical procedure." Teaching evaluations were significantly more positive during a year when the jigsaw was used than a prior year when it was not used $(p<.001)$. Also, students' overall scores on tests assessing material covered in the jigsaw procedure improved significantly from pre- to post- jigsaw $(p<.05)$.

Aronson and Bridgeman (1979, pp. 439-443) identified several factors as responsible for the success of the jigsaw procedure in improving student performance; these included positive changes in students' participation, empathy, interdependence, equal status contact, and attributions. Subsequent studies (e.g., Desforges et al., 1991; Dovidio, Gaertner, \& Validzic, 1998; Eilks, 2005; Hänze \& Berger, 2007; Meyers, 1998; Walker \& Crogan, 1998) have examined different combinations of these factors in both experimental and field settings and support Aronson's and Bridgeman's theorizing concerning the procedure's impact on student outcomes. These studies have shown that, relative to assignments requiring students to work individually, the jigsaw procedure provides students more opportunities for equal status contact with other student colleagues in solving problems that require interdependence and amplifies the importance of group members' independent contributions.

Aronson and Bridgeman (1979, p. 439) also discussed the potentially harmful effects of perceived unfairness in the classroom, arguing that perceived unfairness may lead students to believe that instructors regard some students as lower in status than others, which in turn can disrupt cooperation and performance. This important observation has received little attention, however, in subsequent jigsaw studies. A notable exception is Carroll (1986), which assessed students' fairness perceptions, intellectual motivation, and knowledge gained in an undergraduate psychology laboratory course that utilized the jigsaw procedure. In that study, the procedure led to high mean ratings of fairness of the grading system, as expected (mean fairness was 4.04 out of 5 , across three years). Also as predicted, participants assigned high ratings to knowledge gained from and degree of intellectual motivation in the course (mean ratings were 4.19 and 4.41 out of 5, respectively, across three years). However, this study neither included an alternative instructional procedure for comparison to the jigsaw nor examined relationships among fairness ratings and other ratings. Inclusion of a comparison condition would have provided valuable information about the extent to which the jigsaw procedure is perceived as fairer, and more satisfying, than other procedures. Examination of relationships among fairness and other ratings would have revealed the importance of fairness, relative to other factors known to result from using the jigsaw.

\subsection{Overview of Study and Summary of Hypotheses}

In the present study, students in an undergraduate research methods and statistics course completed two lab assignments as part of jigsaw groups and two more traditional lab assignments that required students to work individually. Both the jigsaw group assignments and the more traditional individual statistics lab assignments were designed to provide students with opportunities to use in novel ways complex concepts previously covered in lectures to solve realistic statistics problems. Although the sample size was small, this investigation provides valuable insight into the impact of unfairness in the process through which the jigsaw strategy facilitates retention, application, and mastery of psychological statistics, and its findings were robust and, in most cases, significant.

Previous jigsaw classroom studies have shown that, relative to traditional assignments, jigsaw group assignments provide students with more opportunities for equal status contact with fellow students in solving problems that require interdependence and highlight independent contributions. On the basis of this research, we predicted the following main effects: relative to more traditional individual statistics lab assignments, jigsaw group assignments should be considered fairer (Hypothesis 1a) and more satisfying (Hypothesis 1b).

Grades on the "traditional" assignments our students completed were determined solely by their individual effort in completing the assignment, whereas grades on the jigsaw group assignments were determined by students' levels of individual effort, as well as the collective effort of their respective jigsaw groups. Consequently, on the basis of procedural fairness research, we reasoned that procedural fairness ratings for the traditional assignments would reflect instrumental concerns, while procedural fairness ratings of the jigsaw group assignments would reflect both instrumental and relational concerns. We assumed that another difference between the two types of assignments was the jigsaw group assignments afforded students with increased opportunities to present their views and have them considered in determining the best solution to a problem (i.e., voice), whereas the traditional assignments did not. Many previous procedural fairness studies have shown that high-voice procedures, relative to low-voice procedures, are perceived to be fairer and convey more positive relational information. Combining these insights, we 
hypothesized there should be no relationship between relational ratings and procedural fairness ratings of the traditional assignments (Hypothesis 2a) and the relationship between relational ratings and procedural fairness ratings of the jigsaw assignments should be significant and should be mediated by perceived voice (Hypothesis $2 b$ ).

Previous jigsaw classroom and procedural fairness studies suggest that students' fairness and satisfaction ratings for the jigsaw assignments should be positively related. Therefore, we hypothesize procedural fairness and satisfaction judgments for the jigsaw assignment should be positively correlated (Hypothesis 3a). The jigsaw classroom and procedural fairness literatures both would suggest this is the case, because perceived fairness of the jigsaw procedure communicates to students that they are valued members of a group (their jigsaw group), which is psychologically rewarding. Specifically, it is predicted that as perceptions of the jigsaw procedure's fairness increase, students' feelings about their jigsaw group members (e.g., liking for, trust for, and perceived consensus among group members) will increase, leading in turn to higher satisfaction ratings. Hence, procedural fairness and satisfaction judgments for the jigsaw assignment should be mediated by group identification (Hypothesis $3 b$ ).

The procedural fairness literature would suggest a similar positive correlation between procedural fairness and satisfaction ratings for the traditional procedure. Therefore, procedural fairness and satisfaction judgments for the traditional assignment should be positively correlated (Hypothesis 3c). However, given that students' outcomes in the traditional assignment were determined solely on the basis of individual effort, we reasoned that fairness judgments would derive from students' self-interest concerns about success in the class, and consequently would be linked to satisfaction ratings as a consequence of instrumental concerns alone.

Finally, given the emphasis within group value theory on voice and group identification - the two primary features assumed to distinguish the jigsaw procedure from the traditional procedure-as determinants of group commitment (e.g., Tyler, Degoey, \& Smith, 1996), we hypothesized reactions to the jigsaw procedure should be more important predictors of commitment to the class than reactions to the traditional procedure (Hypothesis 4).

\section{Method}

\subsection{Participants}

Participants were 46 students enrolled in an undergraduate psychology research methods and statistics course at a research university located on the East Coast. At midterm and at the end of the semester, students anonymously completed standard teaching evaluation forms and questionnaires to provide the instructor feedback on their perceptions of the effectiveness of their lab assignments. The instructor informed the students that responding was completely voluntary, and students received neither class credit nor payment for participation. Of the 46 students in the class, 28 returned the midterm questionnaire evaluation of their lab assignments, but only 13 completed and returned the semester-end questionnaire in its entirety. Given the low response rate for the semester-end questionnaire evaluation, we focus our discussion of results on the midterm questionnaire evaluation.

\subsection{Procedure}

First, students were given two weeks of class instruction (three 90-minute lectures and one two-hour problem-solving lab) on the chi-square contingency test. During the following class period, students were administered a one-hour quiz (labeled Pre-Jigsaw 1 quiz) covering the material presented to them in lecture and lab.

During the following week's problem-solving lab, students completed a group assignment (labeled Jigsaw 1), which required them to apply their knowledge of the concepts on which they were tested in the Pre-Jigsaw 1 quiz. For this group assignment, students were randomly assigned to work in one of six jigsaw groups, each of which consisted of four or five members. Once in their jigsaw groups, students were given booklets (described in detail below) containing their lab assignment and instructions for completing the assignment, and then randomly assigned one of four subtasks on which they were expected to develop expertise. (We hence refer to each group member's assigned subtask as his/ her "expert role." ${ }^{1}$ ) Each of the six jigsaw groups was presented with a different research problem, focusing on the relationship between a pair of variables.

After reviewing the instructions with the lab instructor, students worked individually on their expert role subtasks for approximately 30 minutes. Students from different groups who had been assigned the same expert role then met to formulate solutions to their expert role subtasks for approximately 30 minutes. Next, students returned to their assigned jigsaw groups and were given 30 minutes to present to the group their solutions to their expert role subtasks. Finally, students individually completed a written report of their jigsaw groups' findings for homework. During the following week, the students submitted their written reports and were administered another one-hour quiz (labeled Post-Jigsaw 1 quiz), which included material covered in the jigsaw lab assignment. Students were not allowed to collaborate during the quiz. 
During the problem-solving lab following the Post-Jigsaw 1 quiz, students completed a more traditional lab assignment (labeled Traditional Exercise 1), which required them to apply their knowledge of the concepts on which they were tested in the Pre-Jigsaw 1 quiz and had to be completed individually. For the traditional lab assignment, students were given a description of a research problem focusing on the relationship between a pair of variables, a computer-generated spreadsheet of data that corresponded to the research problem, a brief tutorial on the Chart Wizard and Data Analysis functions in Microsoft Excel, and four subtasks similar to the subtasks involved in the jigsaw group lab assignment. Here, however, students were instructed not to collaborate with other students while completing these subtasks. Again, students completed a written report of their findings for homework due the following week of class. Also, during the following week's quiz, concepts covered in this traditional lab assignment were tested. At the midterm, students completed a questionnaire to evaluate the jigsaw group assignment and the traditional assignment.

The process described above was repeated in the second half of the semester, during which students (a) were randomly assigned to a new jigsaw group, were randomly assigned new expert roles, and completed a second jigsaw group lab assignment involving $t$ tests and linear regression (Jigsaw 2); and (b) individually completed a second traditional lab assignment involving $t$ tests and linear regression (Traditional Exercise 2). Finally, at the end of the semester, students completed another questionnaire to evaluate the second jigsaw group assignment and the second traditional assignment.

\subsection{Materials}

\subsubsection{Jigsaw 1}

For the first jigsaw group lab assignment, students were given a booklet that contained the following items: (a) general instructions, (b) an abstract, (c) a description of their expert role subtasks, (d) a spreadsheet of data simulated for the purposes of the assignment, and (e) output generated by SPSS from a chi-square analysis of the simulated data. The general instructions included a detailed description of how jigsaw groups work and of the required written summary of each group's findings.

Each jigsaw group was given one of six abstracts. Each abstract described a study of one of six social psychological phenomena (compliance, prejudice, stereotyping, intrinsic motivation, loneliness, or belief in a just world), specified operational definitions of the variables under study, and identified the hypotheses being tested. All abstracts were modified versions of abstracts taken from actual social psychological studies (e.g., Lepper, Greene, \& Nisbett, 1973), and students were given complete citations for the studies on which their respective assigned abstracts were based.

All students were given descriptions of their expert role assignments. Students who were assigned Expert Role 1 were instructed to identify "the research question, variables of interest, and hypotheses to be tested" in the abstract provided. Students who were assigned Expert Role 2 were instructed to "compute the appropriate descriptive statistics" using the provided simulated data. Students who were assigned Expert Role 3 were instructed to "compute the appropriate inferential statistics" using the provided simulated data. Students who were assigned Expert Role 4 were instructed to "summarize and interpret results" in the provided SPSS chi-square analysis output.

\subsubsection{Traditional Exercise 1}

For the first traditional lab assignment, students were informed they had to complete the assignment by themselves and were given the following instructions: download a dataset from the course website; construct the observed frequency distribution for the dataset using Microsoft Excel (Subtask 1); create a graph of the observed frequency distribution using the Chart Wizard function of Microsoft Excel (Subtask 2); run the appropriate statistical test using the Data Analysis function of Microsoft Excel (Subtask 3); summarize and interpret obtained results (Subtask 4); and submit a brief written summary of the obtained results.

\subsubsection{Jigsaw 2}

For the second jigsaw group lab assignment, again, each jigsaw group was given a booklet containing (a) general instructions, (b) an abstract, (c) a description of their individual expert role assignments, and (d) a spreadsheet of data simulated for the purposes of the assignment. The general instructions for this jigsaw exercise were abbreviated versions of the general instructions for Jigsaw 1; the explanation of how jigsaw groups work was omitted. The general instructions specified a research problem that was to be examined by the jigsaw group and directed each group to provide a written summary of its findings.

Rather than providing students with modified abstracts from actual psychological studies, for the second jigsaw we generated four brief summaries of fictitious studies concerning the following topics: (a) the relationship between 
obesity and cholesterol, (b) the relationship between smoking and cholesterol, (c) the relationship between alcohol consumption and cognitive impairment, and (d) the relationship between chronic fatigue and cognitive impairment. Expert role assignments were as follows: Expert Role 1 students were instructed to conduct a chi-square contingency test; Expert Role 2 students were instructed to conduct an independent-samples $t$ test; Expert Role 3 students were instructed to conduct a correlated-samples $t$ test; Expert Role 4 students were instructed to carry out a linear regression analysis.

\subsubsection{Traditional Exercise 2}

For the second traditional lab assignment, students were informed they had to complete the assignment by themselves and were given the following instructions: download a dataset from the course website; compute summary statistics (mean, standard deviation, and variance) (Subtask 1); run a $t$ test using Microsoft Excel's Data Analysis function (Subtask 2); conduct a linear regression analysis using Microsoft Excel's Data Analysis function (Subtask 3); summarize and interpret obtained results (Subtask 4); and submit a brief written summary of the obtained results.

\subsection{Dependent Measures}

\subsubsection{Satisfaction With the Jigsaw Procedure}

Following Perkins and Saris (2001), students were asked the following five questions: (a) "Was the jigsaw exercise useful for getting help;" (b) "Was the jigsaw exercise useful for giving help;" (c) "Was the jigsaw exercise useful for working with classmates;" (d) "Was the jigsaw exercise useful for providing an alternative to lecture;" and (e) "Was the jigsaw exercise useful for understanding the statistical procedure." Students were asked to indicate their responses on 11-point scales, with response options ranging from 0 (not at all useful) to 10 (very useful). Responses to the five items were averaged and the internal reliability $(\alpha)$ of the scale was .84 .

\subsubsection{Satisfaction With the Traditional Procedure}

Students were asked the following four questions: (a) "Was the Microsoft Excel exercise useful for getting help;" (b) "Was the Microsoft Excel exercise useful for working with classmates;" (c) "Was the Microsoft Excel exercise useful for providing an alternative to lecture;" and (d) "Was the Microsoft Excel exercise useful for understanding the statistical procedure." Again, students indicated their responses on 11-point scales, with response options ranging from 0 (not at all useful) to 10 (very useful). Responses to the four items were averaged and the scale's internal reliability $(\alpha)$ was .74 .

\subsubsection{Group Identification}

Students responded to the following seven items adapted from the Hinkle, Taylor, Fox-Cardamone, and Crook (1989) Group Identity Scale: (a) "I do not consider my jigsaw group to be important;" (b) "I identify with my jigsaw group;" (c) "I perceived a great deal of consensus among my fellow jigsaw group members on the choices that were made;" (d) "My jigsaw group was cohesive;" (e) "I liked my jigsaw group members;" (f) "I trust the other members of my jigsaw group;" and (g) "I was not able to tell if there was any agreement among my jigsaw group about how best to complete the task." Students were asked to indicate on 11-point scales the extent to which they agreed with each statement, with response options ranging from 0 (strongly disagree) to 10 (strongly agree). Responses to items (a) and $(\mathrm{g})$ were reverse-coded and then averaged with the remaining five items, and the scale's internal reliability $(\alpha)$ was .89 .

\subsubsection{Perceived Procedural Fairness}

Students responded to one question about their perception of the fairness of the jigsaw procedure and one question about the fairness of the traditional procedure. Specifically, students were asked the following: (a) "To what extent was the jigsaw group exercise conducted fairly;" and (b) "To what extent was the Microsoft Excel exercise conducted fairly." Students indicated responses on 11-point scales, with response options ranging from 0 (very unfair) to 10 (very fair).

\subsubsection{Perceived Voice}

Two items measured the extent to which students believed that the jigsaw procedure provided them with increased voice. The items were as follows: (a) "I had a lot of opportunity to present my views about how my jigsaw group's problem should be solved;" and (b) "My views were considered and taken into account." Responses were indicated on 11-point scales, with response options ranging from 0 (strongly disagree) to 10 (strongly agree). Responses to the two items were averaged, and the scale's internal reliability $(\alpha)$ was .84 . 


\subsubsection{Perceived Value}

Students responded to two items that measured the extent to which they perceived that they and other students were valued by the instructor: (a) "To what extent do you feel your needs are being taken into account;" and (b) "To what extent do you feel that the instructor values students." Students indicated level of agreement with each item on 11-point scales with response options ranging from 0 (strongly disagree) to 10 (strongly agree). Responses to the two items were averaged, and the scale's internal reliability $(\alpha)$ was .57 .

\subsubsection{Commitment}

As measures of commitment, students responded to two items about the level of effort they anticipated putting forth in future jigsaw group assignments, in particular, and in the class, in general: (a) "How much future effort do you anticipate putting forth in similar group activities;" and (b) "How much future effort do you anticipate putting forth in the class." Responses to both items were indicated by students on 11-point scales with response options ranging from 0 (none at all) to 10 (a great deal). Responses to the two items were averaged, and the scale's internal reliability ( $\alpha$ ) was .91.

\section{Results}

\subsection{Preliminary Analyses}

We examined two sources of evidence of the jigsaw procedure's effectiveness, following similar past studies (e.g., Carroll, 1986): students' evaluations of the jigsaw procedure and students' mastery of the statistical concepts that were covered in the jigsaw exercises. Consistent with earlier studies, students' evaluations of the jigsaw procedure were very positive in this study. Mean ratings of (a) satisfaction with the jigsaw, (b) perceived fairness of the jigsaw, and (c) commitment to the course were $7.58(S E=.25), 8.31(S E=.23)$, and $8.96(S E=.24)$ out of 10, respectively. Further, more than $50 \%$ of the respondents $(n=26)$ gave mean ratings of 7.94 or higher for these measures.

Mastery measures obtained in this study also suggest the jigsaw procedure was effective. Scores on quiz questions covering concepts involved in the jigsaw improved significantly from pre- to post-jigsaw, $t(22)=1.80, p=.04$ (one-tailed), $d=.38$ for Jigsaw 1 , and $t(18)=2.01, p=.03$ (one-tailed), $d=.46$ for Jigsaw 2 . Students answered, on average, 68\% ( $S E=.07)$ of the Pre-Jigsaw 1 chi-square questions correctly and $83 \%(S E=.05)$ of the Post-Jigsaw 1 chi-square questions correctly. Students answered 60\% ( $S E=.09)$ of the Pre-Jigsaw $2 t$-test and regression questions correctly and $83 \%(S E=.06)$ of the Post-Jigsaw $2 t$-test and regression questions correctly. The magnitude of improvement observed here was similar to that observed in Perkins and Saris (2001).

\subsection{Differences in Reactions to the Jigsaw Procedure and the Traditional Procedure}

We hypothesized that fairness and satisfaction ratings of the jigsaw procedure would be higher than fairness and satisfaction ratings of the traditional procedure (i.e., Hypotheses $1 \mathrm{a}$ and $1 \mathrm{~b}$, respectively). To test these hypotheses, we compared differences in students' fairness and satisfaction ratings of the jigsaw and traditional procedures. Hypothesis 1a was not confirmed; procedural fairness ratings were only slightly higher for the jigsaw procedure $(M=$ $8.31, S E=.23)$ than for the traditional procedure $(M=8.25, S E=.33), t(25)=.19, p=.42$ (one-tailed), $d=.04$. Hypothesis $1 \mathrm{~b}$ was supported; students were significantly more satisfied with the jigsaw procedure $(M=7.53, S E$ $=.25)$ than with the traditional procedure $(M=6.95, S E=.36), t(23)=1.86, p=.04$ (one-tailed), $d=.38$.

\subsection{Explaining Fairness}

We predicted that relational judgments would not be related to procedural fairness judgments of the traditional procedure, but would be related to procedural fairness ratings of the jigsaw procedure. In order to test these hypotheses ( $2 \mathrm{a}$ and $2 \mathrm{~b}$, respectively), we examined the correlations between ratings of perceived value (evaluations of the extent to which the instructor valued students and took their needs into account) and procedural fairness for the traditional and for the jigsaw procedure. As expected, there was a significant positive correlation between perceived procedural fairness and perceived value for the jigsaw procedure, $r(24)=.55, p=.002$ (one-tailed), but not for the traditional procedure, $r(26)=.21, p=.15$ (one-tailed). We attribute this difference to the fact that the jigsaw procedure provides students with more of an opportunity for voice than the traditional procedure. 
Table 1. Summary of regression analyses for variables predicting perceived fairness of the jigsaw procedure

\begin{tabular}{lcccc}
\hline Predictor Set & $B$ & $S E B$ & $\beta$ & Fit Index \\
\hline 1. Perceived Value & .77 & .25 & $.55^{* *}$ & \\
$R^{2}$ & & & & $.30^{* *}$ \\
2. Perceived Value & .39 & .23 & .28 & \\
$\quad$ Perceived Voice & .49 & .14 & $.56^{* *}$ & \\
$R^{2}$ & & & & $.54^{* * *}$ \\
$F$ Statistic for $\Delta R^{2}$ from Predictor Set 1 to 2 & & & & $11.26^{* * *}$ \\
\hline Note. $* p<05 . * * p<.01 . * * * p<.001$ & &
\end{tabular}

Support for this interpretation of these results comes from similar findings in the group value theory literature and from the following mediational analysis: Following Baron and Kenny (1986), we examined the extent to which (a) the independent variable (IV) (perceived value) and the hypothesized mediator (perceived voice) were significantly correlated; (b) the hypothesized mediator (perceived voice) and the dependent variable (DV) (perceived procedural fairness) were significantly correlated; and (c) the inclusion of the mediator (perceived voice) as an additional predictor in the regression of the DV (perceived procedural fairness) on the IV (perceived value) resulted in a decrease in the significance of the correlation between the IV and DV. We found that perceived value and perceived voice were significantly correlated, $r(24)=.48, p=.01$, as expected; perceived voice and perceived procedural fairness were significantly correlated, $r(25)=.69, p<.001$, as expected. Table 1 shows that the inclusion of perceived voice as an additional predictor in the regression of perceived procedural fairness on perceived value resulted in a decrease in the significance of the relationship between perceived value and perceived procedural fairness from $p=.005$ to $p=.107$, as expected. We further tested the proposed mediational effect of perceived voice using a percentile bootstrap estimation approach with 5000 samples with the PROCESS macro Version 3 (Hayes, 2017). The results further supported the mediational effect of perceived voice, inasmuch as the indirect coefficient tested using the Hayes (2017) approach was statistically significant, $B=.38, S E=.22,95 \%$ CI [.06, .91]. Thus, it does appear that relational judgments are positively related to students' fairness perceptions for the jigsaw because the procedure provides an opportunity for voice.

\subsection{Explaining Satisfaction}

We hypothesized that students' fairness and satisfaction ratings would be positively correlated for both the jigsaw and traditional procedures (Hypotheses $3 \mathrm{a}$ and $3 \mathrm{c}$, respectively). Further, we expected the relationship between perceived fairness and satisfaction for the jigsaw procedure to be mediated by group identification (Hypothesis $3 b$ ). This latter prediction is consistent both with previous jigsaw classroom research (e.g., Perkins and Saris, 2001) and previous research on group value theory (e.g., Tyler, Degoey, \& Smith, 1996). We tested the proposed mediational effect of group identification using both the Baron and Kenny (1986) approach and the Hayes (2017) percentile bootstrap estimation approach with 5000 samples using the PROCESS macro Version 3. As expected, we found that students' ratings of procedural fairness were positively correlated with their ratings of satisfaction for both the jigsaw, $r(25)=.56, p=.001$ (one-tailed), and the traditional procedure, $r(25)=.65, p<.001$ (one-tailed). Also, as expected, we found that perceived fairness of the jigsaw procedure and group identification were significantly correlated, $r(23)$ $=.45, p=.01$; group identification and ratings of satisfaction with the jigsaw were significantly correlated, $r(23)$ $=.80, p<.001$; and, as shown in Table 2, the inclusion of group identification as an additional predictor in the regression of these satisfaction ratings on procedural fairness ratings resulted in a decrease in the significance of the relationship between satisfaction and procedural fairness from $p=.009$ to $p=.154$. The results further supported the mediational effect of group identification, inasmuch as the indirect coefficient tested using Hayes' approach (2017) was statistically significant, $B=.33, S E=.16,95 \% \mathrm{CI}=[.09, .74]$. 
Table 2. Summary of regression analyses for variables predicting satisfaction with the jigsaw procedure

\begin{tabular}{llccc}
\hline Predictor Set & $B$ & $S E B$ & $\beta$ & Fit Index \\
\hline 1. Perceived Procedural Fairness & .55 & .19 & $.52^{* * *}$ & \\
$\quad R^{2}$ & & & & $.27^{* *}$ \\
2. Perceived Procedural Fairness & .22 & .15 & .21 & \\
$\quad$ Group Identification & .57 & .11 & $.71^{* * *}$ & \\
$R^{2}$ & & & & $.67^{* * *}$ \\
$\quad F$ Statistic for $\Delta R^{2}$ from Predictor Set 1 to 2 & & & & $25.44^{* * *}$ \\
\hline
\end{tabular}

Note. $* p<05 . * * p<.01 . * * * p<.001$

\subsection{Explaining Commitment}

Finally, we examined additive and moderating effects on commitment to the class of (a) perceived fairness of and satisfaction with the jigsaw procedure, (b) perceived fairness of and satisfaction with the traditional procedure, (c) perceived voice afforded by the jigsaw procedure, (d) perceptions of the extent to which the instructor valued students, and (e) identification with the jigsaw group. To pursue this interest, we used the backward elimination regression command in SPSS and added a group identification by perceived voice interaction term to the list of predictors. The group identification by perceived voice interaction term was created by multiplying group identification and perceived voice scores. To reduce multicollinearity, perceived voice and group identification scores were mean-centered prior to performing the multiplication.

Table 3. Summary of backward elimination regression analysis for variables predicting commitment

\begin{tabular}{|c|c|c|c|c|c|}
\hline \multicolumn{2}{|c|}{ Predictor Set } & $B$ & $S E B$ & $\beta$ & Fit Index \\
\hline & Perceived Value & .64 & .29 & $.42^{\dagger}$ & \\
\hline & Perceived Voice & -.41 & .18 & $-.43^{*}$ & \\
\hline & Group Identification & 1.04 & .21 & $1.15^{* * *}$ & \\
\hline & Perceived Voice $\times$ Group Identification & -.39 & .15 & $-.56^{*}$ & \\
\hline & Perceived Fairness of Traditional Procedure & -.29 & .15 & $-.32^{\dagger}$ & \\
\hline & Perceived Fairness of Jigsaw Procedure & -.17 & .22 & -.16 & \\
\hline & Satisfaction with Traditional Procedure & -.14 & .21 & -.10 & \\
\hline & Satisfaction with Jigsaw Procedure & .04 & .27 & .03 & \\
\hline \multicolumn{2}{|l|}{$R^{2}$} & & & & $.85^{* * *}$ \\
\hline \multirow[t]{7}{*}{2.} & Perceived Value & .65 & .28 & $.43^{*}$ & \\
\hline & Perceived Voice & -.41 & .17 & $-.42^{*}$ & \\
\hline & Group Identification & 4.16 & 1.14 & $4.62^{* *}$ & \\
\hline & Perceived Voice $\times$ Group Identification & -.39 & .13 & $-5.83^{*}$ & \\
\hline & Perceived Fairness of Traditional Procedure & -.30 & .13 & $-.33^{*}$ & \\
\hline & Perceived Fairness of Jigsaw Procedure & -.17 & .21 & -.16 & \\
\hline & Satisfaction with Traditional Procedure & -.13 & .20 & -.10 & \\
\hline \multicolumn{2}{|l|}{$R^{2}$} & & & & $.85^{* * *}$ \\
\hline \multicolumn{2}{|c|}{$F$ Statistic for $\Delta R^{2}$ from Predictor Set 2 to 1} & & & & .02 \\
\hline \multirow[t]{3}{*}{3.} & Perceived Value & .66 & .27 & $.43^{*}$ & \\
\hline & Perceived Voice & -.39 & .17 & $-.40^{*}$ & \\
\hline & Group Identification & 1.06 & .16 & $1.17^{* * *}$ & \\
\hline Publ & hed by Sciedu Press & & ISS $\Lambda$ & 183 E-IS & $2380-9205$ \\
\hline
\end{tabular}




\begin{tabular}{|c|c|c|c|c|c|}
\hline & Perceived Voice $\times$ Group Identification & -.39 & .13 & $-.58^{*}$ & \\
\hline & Perceived Fairness of Traditional Procedure & -.34 & .11 & $-.38^{* *}$ & \\
\hline & Perceived Fairness of Jigsaw Procedure & -.19 & .21 & -.18 & \\
\hline \multicolumn{5}{|l|}{$R^{2}$} & $.84^{* * * *}$ \\
\hline \multicolumn{5}{|c|}{$F$ Statistic for $\Delta R^{2}$ from Predictor Set 3 to 2} & .43 \\
\hline 4. & Perceived Value & .51 & .22 & $.34^{*}$ & \\
\hline & Perceived Voice & -.48 & .13 & $-.50^{* *}$ & \\
\hline & Group Identification & .96 & .13 & $1.06^{* * * *}$ & \\
\hline & Perceived Voice $\times$ Group Identification & -.32 & .11 & $.47^{* *}$ & \\
\hline & Perceived Fairness of Traditional Procedure & -.32 & .10 & $-.36^{* *}$ & \\
\hline \multicolumn{5}{|l|}{$R^{2}$} & $.84^{* * * *}$ \\
\hline \multicolumn{5}{|c|}{$F$ Statistic for $\Delta R^{2}$ from Predictor Set 4 to 3} & .82 \\
\hline
\end{tabular}

Note. ${ }^{\dagger} p<.1$, marginally significant. $* p<05 . * * p<.01 . * * * p<.001$

Table 3 shows that the most efficient explanatory model for commitment included the following predictors: perceived value $(\beta=.34, p=.03)$, perceived voice $(\beta=-.50, p=.002)$, group identification $(\beta=1.06, p<.001)$, perceived voice $\times$ group identification $(\beta=-.47, p=.008)$, and perceived fairness of the traditional procedure $(\beta=$ $-.36, p=.008){ }^{2}$ Consistent with group value theory, perceived value and group identification were positively correlated with commitment. However, the significant perceived voice by group identification interaction suggests that when perceived voice is high, group identity has a bigger effect on commitment than when perceived voice is low. This interpretation is supported by partial correlations of group identification and commitment, controlling for all the other significant predictors in the most explanatory model (i.e., perceived value, fairness of the traditional procedure and the perceived voice by group identification interaction). When perceived voice is high (as determined by a median split), group identification is significantly positively related to commitment, $r(6)=.69, p=.03$. However, when voice is low, group identification is not significantly related to commitment $r(4)=.47, p=.17$. Furthermore, when voice is high, group identification explains approximately $48 \%$ of the variance in commitment, after controlling for all the other significant predictors in the most explanatory model $\left(r^{2}=.48\right)$.

Contrary to the procedural fairness literature, perceived fairness of the traditional procedure and commitment were negatively related. One possible explanation for this derives from the fact that the traditional procedure allowed students to use statistical analysis software. Indeed, in class, students often expressed frustration after learning that a statistical test that required many tedious steps manually could be calculated easily using software. This suggests the importance of explaining to students the value of manual computations of statistical tests.

\section{Discussion}

The jigsaw procedure's effectiveness has been demonstrated in numerous previous jigsaw studies (e.g., Perkins \& Saris, 2001). We found evidence supportive of the jigsaw procedure's effectiveness (e.g., pre-/ post-jigsaw elevated performance on examinations for two different jigsaw group assignments involving complex statistical concepts; highly positive student evaluations of jigsaw assignments) as well. Our overarching interest here, however, was not in demonstrating that the jigsaw classroom works and leads to more positive evaluations of instructors (in general or in psychological statistics classes specifically). Rather, our objective was to extend and build on previous research by examining the jigsaw procedure's effect on students' fairness perceptions. To accomplish this objective, we examined the effect of a jigsaw group assignment, relative to a more traditional individual assignment (used as a comparison condition), on students' fairness ratings, satisfaction ratings, inferences about the extent to which the instructor valued them, and ratings of anticipated effort on future class assignments (commitment). Further, we examined the extent to which perceived voice and group identification mediated the relationships between perceptions of fairness, satisfaction, and the instructor.

Our jigsaw and traditional assignments were designed to afford students opportunities to apply statistical concepts previously discussed in class in new ways. However, the jigsaw assignments required students to work both independently and interdependently, whereas the traditional assignments only required students to work independently. Because the jigsaw and traditional assignments both provided students with opportunities to develop 
further their understanding of difficult concepts - to have practical experience applying concepts not otherwise available in lecture - it is not surprising that both were considered highly fair and satisfying. Previous jigsaw classroom research would suggest the jigsaw procedure should be considered fairer and more satisfying than the traditional procedure, and we found that the jigsaw was considered only slightly fairer than the traditional procedure ( $M=8.31$ vs. 8.25 , respectively), but significantly more satisfying ( $M=7.53$ vs. 6.95 , respectively).

Procedural fairness ratings were assumed to be determined differently in the traditional and jigsaw conditions. In the former, the primary influence was assumed to be instrumental concerns; in the latter, both instrumental and relational concerns resulting from the collective effort of group involvement were assumed. In addition, voice (the expression of one's views) was regarded as an important influence in the jigsaw condition. Combining these insights, we expected no relationship between relational and procedural fairness ratings of the traditional assignment, and we expected the relationship between relational and procedural fairness ratings of the jigsaw to be significant and to be mediated by perceived voice. And, indeed, this is what we found. This pattern of findings demonstrates that in addition to the known influences of the jigsaw, voice is an important intervening variable in the relationship between students' attributions about their instructor and fairness perceptions.

Tasks that are regarded as high in procedural fairness are also considered more satisfying (see, e.g., Brockner \& Wiesenfeld, 1996). Consequently, we expected a positive correlation between perceptions of procedural fairness and satisfaction for both the jigsaw and traditional assignments, but for different reasons. We posited satisfaction judgments in the traditional condition would be linked to fairness judgments solely because of students' concerns about success in the class, whereas in the jigsaw condition these judgments would result from students' concerns about success in the class as well, in addition to their relational concerns and sense of group identity. As expected, our findings show a positive association between procedural fairness and satisfaction judgments in both conditions, and that this association was mediated by group identification in the jigsaw condition. These findings are important for two reasons. First, they establish the ecological validity of fair process effects in a setting not previously investigated. Second, they extend previous jigsaw classroom research by providing preliminary empirical support for Aronson's and colleagues' position that the success of the jigsaw is due in part to decreased perceptions of unfairness.

We found that group identification and perceived voice were more important predictors of anticipated effort (commitment to the class) than more objective indices of the assigned work (students' evaluations of satisfaction with and fairness of assigned work). This finding is consistent with past studies of both group value theory and social identity theory. Group value theory studies have shown that voice is psychologically rewarding, having positive effects on self-esteem and group pride, because it communicates to students that they are valued members of a group (Tyler, Degoey, \& Smith, 1996). Similarly, social identity theory studies have shown that equal status interactions that foster cooperative norms and encourage development of a sense of group identity are psychologically rewarding because these interactions provide individuals with self-validation and emotional support (Tajfel \& Turner, 1986).

Collectively, our findings substantiate many previous findings of positive effects of the jigsaw procedure (e.g., self-esteem and group identification; see Aronson \& Bridgeman, 1979). In addition, they extend the findings in this domain of research by showing the procedure leads to increased perceptions among students that they have a voice, their voice matters, their needs are important, and their instructor values them. These findings suggest, as a consequence, this technique is particularly well-suited for teaching research methods and statistics. Such positive perceptions of voice and value have the potential to decrease anxiety and apprehension, two of the most problematic challenges associated with teaching these classes. As noted earlier, concepts in research methods and statistics are less easily applied and less likely to be retained than concepts in other psychology courses. Jigsaw exercises like the ones described here allow students to use statistical concepts not just in formulaic ways, but in novel ways that increase their likelihood of retention and that clarify connections to related concepts. Additionally, jigsaw group assignments of the sort described in this paper provide students with opportunities to solve the kinds of statistics problems they are likely to encounter as psychologists. Finally, our jigsaw group assignments provide students with practical experience applying concepts, inasmuch as they allow students to collaborate in devising solutions to research problems in much the same way that members of psychological research laboratories collaborate to design studies, analyze data, and write papers.

This study's value to the teaching of psychological statistics is that it allows us to understand further the process through which the jigsaw procedure works and it sheds light on the role of fairness and relational considerations in that process. We find support for theorizing by Aronson and colleagues that fairness is an essential component of the jigsaw procedure's effectiveness as a teaching tool. In order to more closely examine the impact of fairness on 
students' performance, future studies should systematically vary different aspects of fairness and examine their effects on performance. Additionally, future studies should compare the magnitude of students' performance improvement following jigsaw assignments to that obtained following traditional assignments, to further identify the specific role fairness plays in enhancing learning when different teaching methods are employed.

One notable limitation regarding the generalizability of the current findings is low statistical power due to small sample size $(n=28)$. Our statistical power reached a maximum of 0.68 , which is lower that the widely accepted convention of 0.80 (Cohen, 1992). It is quite possible that the non-significant findings were observed because our study lacked enough statistical power to detect these effects. However, we are compelled by the statistically significant performance and satisfaction differences we did find because these effects fell within the moderate effects range ( $d$ ranged between .38 and .46), and thus, were large enough to be detected by our relatively small study sample.

\section{Conclusion}

This study's findings suggest that the jigsaw technique is well-suited for supplementing undergraduate psychological statistics lectures, because its inherent features related to fairness help mitigate some of the unique challenges (e.g., evocation of higher levels of anxiety and apprehension and great difficulties with retention and application than other psychological courses) associated with research methods and statistics. Future studies should examine whether or not students' fairness perceptions importantly affect their performance in other courses in the same manner that they affect students' performance in statistics courses. As Bass (1999) suggests, there is a great need to conduct research that incorporates theoretical insights to elucidate the teaching process and to identify those strategies that make learning more likely and more lasting. Such research would simultaneously advance knowledge within social psychology by addressing social psychological factors, such as fairness and group identity, which are theoretically important to understanding behavior.

\section{References}

Abrami, P. C., Cholmsky, P., \& Gordon, R. (2001). Statistical analysis for the social sciences: An interactive approach. Boston, MA: Allyn and Bacon.

Aronson, E. (1990). Applying social psychology to desegregation and energy conservation, Personality and Social Psychology Bulletin, 16, 118-132. https://doi.org/10.1177/0146167290161009

Aronson, E. (2002). Building empathy, compassion, and achievement in the jigsaw classroom. In J. Aronson (Ed.), Improving academic achievement: Impact of psychological factors on education (pp. 209-225). San Diego, CA: Academic Press. https://doi.org/10.1016/B978-012064455-1/50013-0

Aronson, E., Blaney, N., Sikes, J., Stephan, C., \& Snapp, M. (1975). Busing and racial tension: The jigsaw route to learning and liking. Psychology Today, 8, 43-59.

Aronson, E., \& Bridgeman, D. (1979). Jigsaw groups and the desegregated classroom: In pursuit of common goals. Personality and Social Psychology Bulletin, 5, 438-446. https://doi.org/10.1177/014616727900500405

Baron, R. M., \& Kenny, D. A. (1986). The moderator-mediator variable distinction in social psychological research: Conceptual, strategic, and statistical considerations. Journal of Personality and Social Psychology, 51, 1173-1182. http://dx.doi.org/10.1037/0022-3514.51.6.1173

Bass, R. (1999). The scholarship of teaching: What's the problem?. Inventio: Creative Thinking about Learning and Teaching, $1, \quad 1-10$ Retrieved from http://66.208.62.164/@api/deki/files/1098/=12_RR_Assignment_2_Readings.pdf

Brockner, J., \& Wiesenfeld, B. (1996). An integrative framework for explaining reactions to decisions: Interactive effects of outcomes and procedures. Psychological Bulletin, 120, 189-208. http://dx.doi.org/10.1037/0033-2909.120.2.189

Brookfield, S. D., \& Preskill, S. (1999). Strategies for reporting small-group discussions to the class. College Teaching, 47, 140-144. https://doi.org/10.1080/87567559909595804

Carroll, D. W. (1986). Use of the jigsaw technique in laboratory and discussion classes. Teaching of Psychology, 13, 208-210. https://doi.org/10.1207/s15328023top1304_9

Conners, F. A., Mccown, S. M., \& Roskos-Ewoldsen, B. (1998). Unique challenges in teaching undergraduate statistics. Teaching of Psychology, 25, 40-42. https://doi.org/10.1207/s15328023top2501_12

Cottrell, N. B., Wack, D. L., Sekerak, G. J., \& Rittle, R. H. (1968). Social facilitation of dominant responses by 
presence of an audience and the mere presence of others. Journal of Personality and Social Psychology, 9, 245-250. http://dx.doi.org/10.1037/h0025902

Crone, T. S., \& Portillo, M. C. (2013). Jigsaw variations and attitudes about learning and the self in cognitive psychology. Teaching of Psychology, 40, 246-251. https://doi.org/10.1177/0098628313487451

Darley, J. M., \& Latané, B. (1968). Bystander intervention in emergencies: Diffusion of responsibility. Journal of Personality and Social Psychology, 8, 377-383. http://dx.doi.org/10.1037/h0025589

Darnon, C., Buchs, C., \& Desbar, D. (2012). The jigsaw technique and self-efficacy of vocational training students: A practice report. European Journal of Psychology of Education, 27, 439-449. https://doi.org/10.1007/s10212-011-0091-4

De Cremer, D., \& Van Hiel, A. (2008). Procedural justice effects on self-esteem under certainty versus uncertainty emotions. Motivation and Emotion, 32, 278-287. https://doi.org/10.1007/s11031-008-9090-4

Desforges, D. M., Lord, C. G., Ramsey, S. L., Mason, J. A., Leeuwen, M., West, S. C., \& Lepper, M. R (1991). Effects of structured cooperative contact on changing negative attitudes toward stigmatized social groups. Journal of Personality and Social Psychology, 60, 531-544. http://dx.doi.org/10.1037/0022-3514.60.4.531

Deutsch, M. (1949). An experimental study of the effects of cooperation and competition upon group processes. Human Relations, 2, 199-231. https://doi.org/10.1177/001872674900200301

Dovidio, J. F., Gaertner, S. L., \& Validzic, A. (1998). Intergroup bias: Status, differentiation, and a common in-group

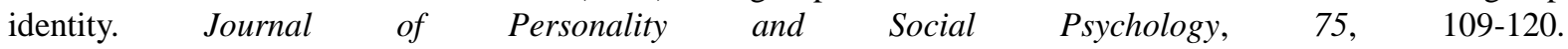
http://dx.doi.org/10.1037/0022-3514.75.1.109

Eilks, I. (2005). Experiences and reflections about teaching atomic structure in a jigsaw classroom in lower secondary school chemistry lessons. Journal of Chemical Education, 82, 313. https://doi.org/10.1021/ed082p313

Folger, R. (1984). The sense of injustice: Social psychological perspectives. New York, NY: Plenum https://doi.org/10.1007/978-1-4613-2683-0

Folger, R., Rosenfield, D., Grove, J., \& Corkran, L. (1979). Effects of voice and peer opinions on responses to inequity. Journal of Personality and Social Psychology, 37, 2253-2261. http://dx.doi.org/10.1037/0022-3514.37.12.2253

Hänze, M., \& Berger, R. (2007). Cooperative learning, motivational effects, and student characteristics: An experimental study comparing cooperative learning and direct instruction in 12th grade physics classes. Learning and Instruction, 17, 29-41. https://doi.org/10.1016/j.learninstruc.2006.11.004

Hayes, A. F. (2017). Introduction to mediation, moderation, and conditional process analysis: A regression-based approach. New York: Guilford Publications.

Heuer, L., Penrod, S., Hafer, C. L., \& Cohn, I. (2002). The role of resource and relational concerns for procedural justice. Personality and Social Psychology Bulletin, 28, 1468-1482. https://doi.org/10.1177/014616702237575

Hildreth, J. D., Moore, D. A., \& Blader, S. L. (2014). Revisiting the instrumentality of voice: Having voice in the process makes people think they will get what they want. Social Justice Research, 27, 209-230. https://doi.org/10.1007/s11211-014-0211-9

Hinkle, S., Taylor, L., Fox-Cardamone, D. L., \& Crook, K. (1989). Intragroup identification and intergroup differentiation: A multicomponent approach. British Journal of Social Psychology, 28, 305-317. https://doi.org/10.1111/j.2044-8309.1989.tb00874.x

Houlden, P., LaTour, S., Walker, L., \& Thibaut, J. (1974). Preferences for modes of dispute resolution as a function of process and decision control. Journal of Experimental Social Psychology, 14, 13-30. https://doi.org/10.1016/0022-1031(78)90057-4

Huang, Y., Liao, Y., Huang, S., \& Chen, H. (2014). A jigsaw-based cooperative learning approach to improve learning outcomes for mobile situated learning. Journal of Educational Technology and Society, 17, 128-140. Retrieved from http://www.jstor.org/stable/jeductechsoci.17.1.128

Kerlinger, F. N., \& Lee, H. B. (2000). Foundations of behavioral research (3rd ed.). New York, NY: Harcourt College.

Langlois, S. C. (2001). Helping students put together pieces of the statistical puzzle with cooperative learning. 
Measurement in Physical Education and Exercise Science, 5, 117-119. https://doi.org/10.1207/S15327841MPEE0502_5

Latané, B., Williams, K., \& Harkins, S. (1979). Many hands make light the work: The causes and consequences of social loafing. Journal of Personality and Social Psychology, 37, 822-832. http://dx.doi.org/10.1037/0022-3514.37.6.822

LaTour, S. (1978). Determinations of participant and observer satisfaction with adversary and inquisitorial modes of adjudication. Journal of Personality and Social Psychology, 36, 1531-1545. http://dx.doi.org/10.1037/0022-3514.36.12.1531

Lepper, M., Greene, D., \& Nisbett, R. (1973). Undermining children's intrinsic interest with extrinsic reward: A test of the 'overjustification' hypothesis. Journal of Personality and Social Psychology, 28, 129-137. http://dx.doi.org/10.1037/h0035519

Lind, E. A., \& Tyler, T. R. (1988). The social psychology of procedural justice. New York, NY: Plenum. https://doi.org/10.1007/978-1-4899-2115-4

Meyers, S. A. (1998). Increasing student participation and productivity in small-group activities for psychology classes. Teaching of Psychology, 24, 105-115. https://doi.org/10.1207/s15328023top2402_5

Perkins, D., \& Saris, R. (2001). A 'jigsaw classroom' technique for undergraduate statistics courses. Teaching of Psychology, 28, 111-113. https://doi.org/10.1207/S15328023TOP2802_09

Şahin, A. (2011). Effects of jigsaw iii technique on achievement in written expression. Asia Pacific Education Review, 12, 427-435. https://doi.org/10.1007/s12564-010-9135-8

Sherif, M., Harvey, O. J., White, J., Hood, W., \& Sherif, C. (1961). Intergroup conflict and cooperation: The robber's cave experiment. Norman, OK: University of Oklahoma Institute of Intergroup Relations.

Tajfel, H., \& Turner, J. C., (1986). The social identity theory and intergroup behavior. In S. Worchel \& W.G. Austin (Eds.), Psychology of intergroup relations (pp. 7-24). Chicago, IL: Nelson-Hall.

Thibaut, J., \& Walker, L. (1975). Procedural justice: A psychological analysis. Hillsdale, NJ: Erlbaum.

Thibaut, J., \& Walker, L. (1978). A theory of procedure. California Law Review, 66, 541-566. https://doi.org/10.2307/3480099

Tyler, T. R. (1989). The psychology of procedural justice: A test of the group-value model. Journal of Personality and Social Psychology, 57, 830-838. http://dx.doi.org/10.1037/0022-3514.57.5.830

Tyler, T. R. (1994). Psychological models of the justice motive: Antecedents of distributive and procedural justice. Journal of Personality and Social Psychology, 67, 850-863. http://dx.doi.org/10.1037/0022-3514.67.5.850

Tyler, T. R., \& Caine, A. (1981). The influence of outcomes and procedures on satisfaction with formal leaders. Journal of Personality and Social Psychology, 41, 642-655. http://dx.doi.org/10.1037/0022-3514.41.4.642

Tyler, T. R., \& Degoey, P. (1995). Collective restraint in social dilemmas: Procedural justice and social identification effects on support for authorities. Journal of Personality and Social Psychology, 69, 482-497. http://dx.doi.org/10.1037/0022-3514.69.3.482

Tyler, T. R., Degoey, P., \& Smith, H. (1996). Understanding why the justice of group procedures matters: A test of the psychological dynamics of the group-value model. Journal of Personality and Social Psychology, 70, 913-930. http://dx.doi.org/10.1037/0022-3514.70.5.913

Tyler, T. R., \& Lind, E. A. (1992). A relational model of authority in groups. In M. Zanna (Ed.), Advances in experimental social psychology (pp. 115-191). New York, NY: Academic Press. https://doi.org/10.1016/S0065-2601(08)60283-X

van den Bos, K. (1999). What are we talking about when we talk about no-voice procedures? On the psychology of the fair outcome effect. Journal of Experimental Social Psychology, 35, 560-577. https://doi.org/10.1006/jesp.1999.1393

van den Bos, K. (2001). Uncertainty management: The influence of uncertainty salience on reactions to perceived procedural fairness. Journal of Personality and Social Psychology, 80, 931-941. http://dx.doi.org/10.1037/0022-3514.80.6.931

van den Bos, K. (2003). On the subjective quality of social justice: The role of affect as information in the 
psychology of justice judgments. Journal of Personality and Social Psychology, 85, 482-498. http://dx.doi.org/10.1037/0022-3514.85.3.482

van den Bos, K., Bruins, J., Wilke, H. A. M., \& Dronkert, E. (1999). Sometimes unfair procedures have nice aspects: On the psychology of the fair process effect. Journal of Personality and Social Psychology, 77, 324-336. http://dx.doi.org/10.1037/0022-3514.77.2.324

van den Bos, K., Lind, E. A., Vermunt, R., \& Wilke, H. A. M. (1997). How do I judge my outcome when I do not know the outcome of others? The psychology of the fair process effect. Journal of Personality and Social Psychology, 72, 1034-1046. http://dx.doi.org/10.1037/0022-3514.72.5.1034

van den Bos, K., \& Miedema, J. (2000). Toward understanding why fairness matters: The influence of mortality salience on reactions to procedural fairness. Journal of Personality and Social Psychology, 79, 355-366. http://dx.doi.org/10.1037/0022-3514.79.3.355

van Prooijen, J., van den Bos, K., \& Wilke, H. M. (2002). Procedural justice and status: Status salience as antecedent of procedural fairness effects. Journal of Personality and Social Psychology, 83, 1353-1361. http://dx.doi.org/10.1037/0022-3514.83.6.1353

van Prooijen, J., van den Bos, K., \& Wilke, H. M. (2004). Group belongingness and procedural justice: Social inclusion and exclusion by peers affects the psychology of voice. Journal of Personality and Social Psychology, 86, 66-79. http://dx.doi.org/10.1037/0022-3514.87.1.66

van Prooijen, J., van den Bos, K., \& Wilke, H. M. (2005). Procedural justice and intragroup status: Knowing where we stand in a group enhances reactions to procedures. Journal of Experimental Social Psychology, 41, 664-676. https://doi.org/10.1016/j.jesp.2004.12.003

Walker, I., \& Crogan, M. (1998). Academic performance, prejudice, and the jigsaw classroom: New pieces to the puzzle. Journal of Community Applied Social Psychology, 8, 381-393. https://doi.org/10.1002/(SICI)1099-1298(199811/12)8:6<381::AID-CASP457>3.0.CO;2-6

Walker, L., LaTour, S., Lind, E.A., \& Thibaut, J. (1974). Reactions of participants and observers to modes of $\begin{array}{lllll}\text { adjudication. Journal of Applied Social Psychology, } & 4, & \text { 295-310. }\end{array}$ https://doi.org/10.1111/j.1559-1816.1974.tb02601.x

Zajonc, R. B. (1965). Social facilitation. Science, 149, 269-274. https://doi.org/10.1126/science.149.3681.269

\section{Notes}

Note 1. For groups containing five members, two students were assigned the same expert role.

Note 2. One participant with an extremely large residual (std. residual $=2.46$ ) in the regression of commitment on perceived voice and group identification was omitted before running the backward elimination regression procedure. 